\title{
Threatening Fishing, the Failure to Pursue Sustainable Development Strategies
}

\author{
Vahid Chamanara $^{1}$, Ehsan Kamrani ${ }^{1}$, Mostafa Zahirinia ${ }^{2}$, Kathleen Schwerdtner Mânez ${ }^{3}$. \\ ${ }^{1}$ Faculty of Marine science and Technologies, University of Hormozgan, Iran; ${ }^{2}$ Faculty of Social Sciences, \\ University of Hormozgan, Iran; ${ }^{3}$ Leibniz Center for Tropical Marine Ecology, Bremen, Germany.
}

\begin{abstract}
Increasingly burden of inhabitants growing in coastlines has led to damage in various mangrove expanses. Though these regions play as fish nursery grounds and are actual vital in stock assessments, there is no precise and state-ofthe-art accessible information about them. Herein the catch records in the Qeshm island marine protected area (MPA) was studied by means of 11 stake-nets. Thoroughly, 81 specimens of 69 genera and 63 families were caught, which the main stream of them were discards. The salable fish were undeveloped which were frequently undersized in comparison with $L M_{50}$. For Pampus argenteus as well, lone $15.3 \%$ of the caught those remained in the permissible catch size. Henceforward, this catch conformation would be there an impending hazard to fish stocks. The chief relative abundance and weight based specimens were Dussumieria acuta (10.05\%) and Arius maculatus (5.9\%), respectively. Encompassing seven species, the Clupeidae was the utmost rich family in the catch conformation. Ultimately, overall once yearly catch by aforementioned stake-nets surrounded by the mangrove woodlands in the Qeshm Island marine protected area was appraised to be 186.77-188.75 tonnes, approximately.
\end{abstract}

Key words: Threatening fishing, marine protected area, mangrove, sustainable development

\footnotetext{
*Author for correspondence: v.chamanara@gmail.com
} 


\section{INTRODUCTION}

Residents development in coastlines has instigated many mangrove woodlands to be used in superfluous conducts or else to be repurposed, being misused by untimely practices or even be devastated ${ }^{1,2}$. Even though there is no precise and state-of-theart data on the status quo and magnitude of these expanses, there is unanimity that a noteworthy quantity of these prized reserves are being demolished annually ${ }^{1,3-9}$ which no less than 35 percent of the expanse of mangrove woodlands has been gone astray for the duration of the bygone twofold decades ${ }^{1}$. With more or less half of the world's population (44\%) living contained by $150 \mathrm{~km}$ of a coastlines ${ }^{10}$, heavily settled littoral areas have led to the extensive clearance of mangroves for coastal development, aquaculture, agriculture or resource use. It is appraised that $26 \%$ of mangrove woodlands worldwide are degraded due to overexploitation for fuel-wood and timber production ${ }^{1}$. Thirty eight percent of worldwide mangrove loss has been accredited to the clearance of mangroves merely aimed at aquaculture, approximately ${ }^{11}$. Removal of mangroves for fuel-wood or aquaculture could contribute unswervingly or circuitously toward a number of coastal problems, comprising an alteration in natural tidal flows, shift of the groundwater table, abridged water quality, discharge of toxic wastes, introduction of excess nutrients and changes to natural food chains ${ }^{12}$. As yet, the most recent inquiry specified that worldwide mangrove deforestation endures however by a far abridged ratio flanked by 0.16 and 0.39 percent for every single year stuck between 2000 and $2012^{13,14}$. Generally, there are almost 124 areas worldwide which are enclosed by mangrove woodlands ${ }^{8}$. Iran, as one of these areas has a significant character in the supervision and safeguarding of this unique ecosystem. Mangrove woodlands or mangroves, are distinctive bionetworks which nurture through marine tides ${ }^{15}, 16$, likewise, these mangroves in Iran are the last limit of mangroves distribution in Southwest Asia ${ }^{17}$. Accordingly, they are critically important. Being pure and homogenous, these Mangrove woodlands lack plant variety, nevertheless they are of great faunal diversity ${ }^{18,19}$. On the other hand, as a nursery for marine fishes, they are exceedingly substantial. Having a wide range of shallow waters, steady sedimentation and countless ecological shelters, this area is an appropriate habitation for assortment of fishes ${ }^{20,21}$. As well this region is under protection by Iranian Environmental Organization, it is likewise registered into International Wetlands in the Ramsar Convention ${ }^{22}$. Assumed that mangrove woodlands are the nursery for fisheries reserves in the Persian Gulf, moreover spawning age or larval and juvenile stage of utmost marine species in Persian Gulf are often associated with this area, consequently beside to the traditional existing managing policies of the area which are originally founded on reserves, it is compulsory to comprise this vital area itself to managing policies. Ever since any negligence on the subject of appraisal and safeguarding of the nursery ground of the commercial species could be led into error in computing the stock assessments, as well as decline or damage of lots of endangered species. Hence, get-together proper facts on the status quo of the nursery ground have to be a top priority. Incidentally, absent an adequate amount of and state-of-the-art data on catch conformation as well as particularly the incidents inside the MPA, as well as fishing herein area regardless of inhibited fishing devoid of appropriate license; the catch conformation of artisanal fishermen's stake-nets as lonely one of their fishing gears were scrutinized. The fallouts at the outset, report the fishing status in the protected area, and in addition they depict a clear illustration of the status quo with the intention of pave the way for further researches to reinforce the fundamentals for decision-makers in fisheries, environment and natural resources. Into the bargain to the aforementioned concerns, bestowing catch 
fishing inside MPA would harm it

conformations of stake-nets in three zones surrounded by MPA alongside northwestern coastline of Qeshm Island is of the aims of the present research.

\section{MATERIALS AND METHODS}

Since the strict numeral of stake-nets surrounded by mangrove marine protected area is not clear, 11 stake-nets in three zones on the northwestern coastline of the Qeshm Island were surveyed for one year. The three zones were extended from the Laft to Goran. The ordinarily sandy seashores of Qeshm Island, particularly the shores alongside the mangroves which are often muddy and sandy, as well as auspicious bed slope, appropriate water deepness plus propinquity to the coves and inlets be responsible for looked-for circumstances for launching stake-nets.

In the present survey 11 stake-nets, allocated into five stake-nets in the zone of Laft, three stake-nets in the zone of Tabl and three stake-nets in the zone of Durbeni and Guran were scrutinized. Dissemination of these stake-nets was chosen in such a way which the samples could be explored alongside the edges of the MPA in three zones comprising northern zone (Laft), Central zone (Tabl) and western zone (Durbeni and Guran) (Figure 1). In the absenteeism of comprehensible and apprised information besides with the intention of collect mandatory data around the undertakings inside MPA, field samplings as well as observations, determining the abundance and conformation of the catch, as well as dialogues with fishermen have been done. Furthermore the overall every twelve months catch of stake-nets inside Qeshm MPA has been estimated using Monte Carlo simulation technique based on 1000 replications by means of Bootstrapping technique. According to the volume of catches in any singular stake-net, the entire or portion of the catch were measured and noted down. Identification of species chiefly done in place during field observations furthermore the local name or the Persian/English name of samples have been questioned from the fishermen to being used in supplementary procedures of identifications. In challenging circumstances the samples were transferred to laboratory and identified by means of applicable identification keys. The data were processed and analyzed in the Microsoft Excel v.2013 and IBM SPSS v.23.

\section{RESULTS}

In the present survey the catch conformation of 34 discharges collected from 11 stake-nets were scrutinized. The measurements disclosed that the mesh size were stuck between 15 to $40 \mathrm{~mm}$ bar for the bunt and 20 to $60 \mathrm{~mm}$ bar for the rest of the net. The results disclosed that an overall of 81 species of 69 genera and 63 families of fish were caught by means of stake-nets which some of the utmost significant ones are publicized in Figure 2. Results illustrated that diversity of caught fishes by means of the stake-net in the northern region has 67 species belonging to 55 genera and 42 families, 73 species belonging to 60 genera and 58 families in the central region, and 55 species in the 46 genera and 40 families in the western region. As well as 6 species of crustacean, 6 species of cartilaginous fishes, two species of cephalopods, one species of sea turtles and three seabird species were observed and noted down; Amongst which the principal relative abundance and relative weight of fishes were belonged to the small discard species (Figure 3). 


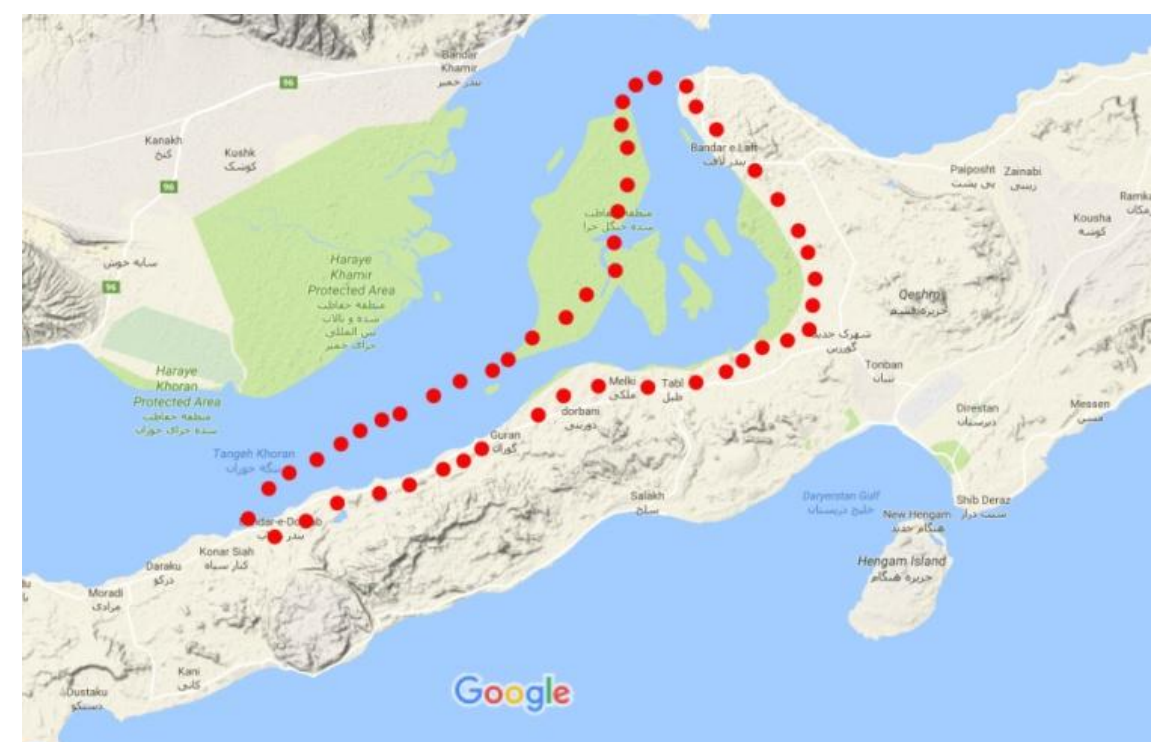

Figure 1 studied area in Qeshm Island northern shoreline (red dots), (source: maps.google.com)

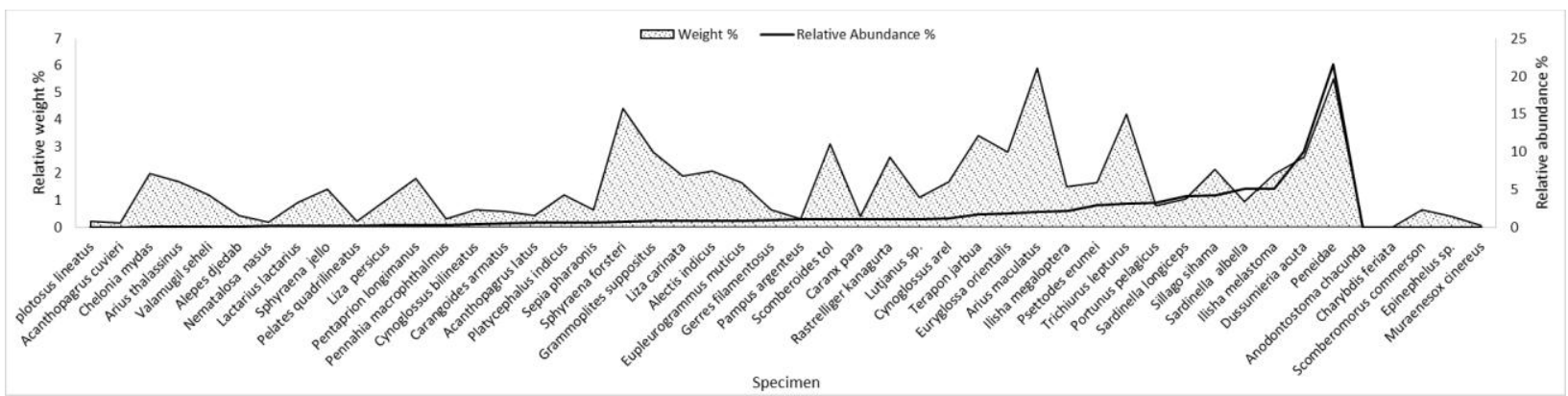

Figure 2 weight percentage of some fish caught in mangrove protected area of Qeshm Island

Table 1. Length for some of the utmost significant caught commercial fish (length in $\mathrm{cm}$ )

\begin{tabular}{lllllll}
\hline Common name & $\begin{array}{l}\text { Min. } \\
\text { Length }\end{array}$ & Max. Length & LM $_{50}{ }^{*}$ & Mode & \% Mode & \% shorter than LM LM $_{50}$ \\
& 8.15 & 24.16 & $18-20$ & 16.61 & 4.73 & 84.7 \\
White pomfret & 10.5 & 19.80 & 23.7 & 14.23 & 8.25 & 100 \\
Yellowfin seabream & 19.28 & 55.4 & 74.2 & 37.85 & 15.63 & 100 \\
Barracuda & 18 & 40.55 & $43.5-64$ & 27.32 & 14.21 & 100 \\
Mero & 18.25 & 42.45 & 85 & 39.91 & 17.64 & 100 \\
Spanish mackerel & & & & & \\
\hline
\end{tabular}

* Source: www.fishbase.org

The results disclosed that utmost of the fish caught belonged to Osteichthyes (Figure $4 \& 5$ ). Moreover, the total length or fork length of some of the utmost significant salable fish are given in Table 1. 
fishing inside MPA would harm it

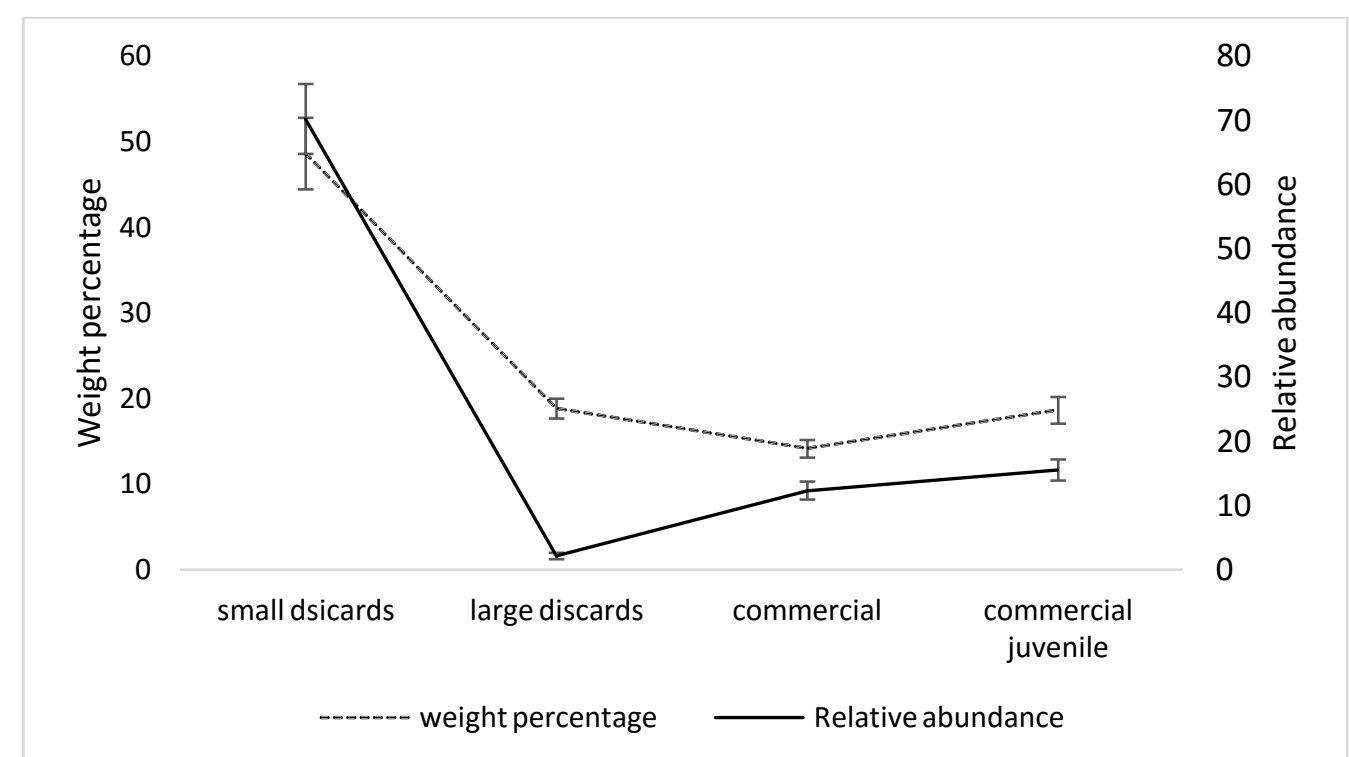

Figure 3 Relative weight/Relative abundance of catch in studied stake-nets

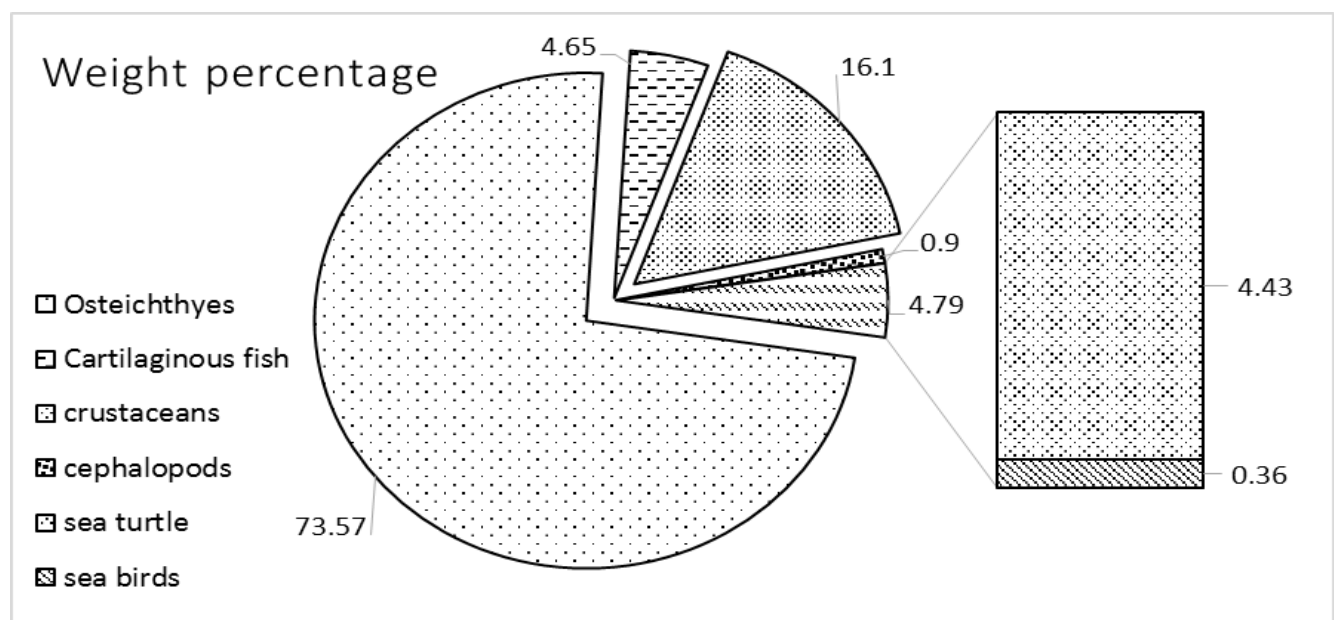

Figure 4 Relative weight of forming groups of catch in studied stake-nets

\section{Relative abundance}

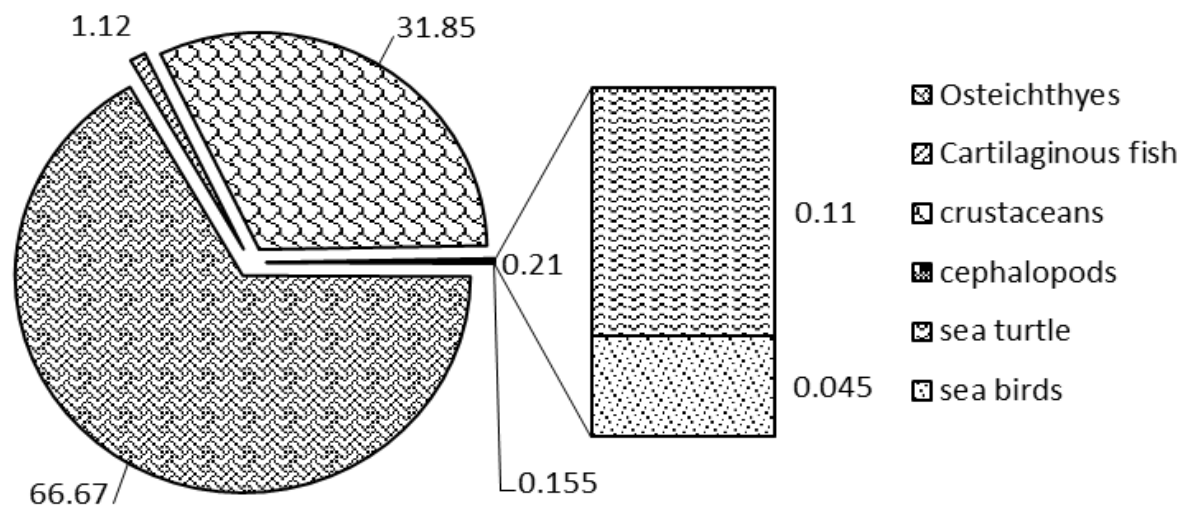

Figure 5 Relative abundance of forming groups of catch in studied stake-nets 
Domino effect of Monte Carlo simulation model revealed that the estimated annual catch inside Qeshm Island MPA in Hormozgan province was flanked by 186.77 and 188.75 tones $(\alpha=0.05)$. These results are illustrated in Table 2.

Table 2 Estimating the annual catch inside Qeshm Island MPA by using Monte Carlo Simulation

\begin{tabular}{|c|c|c|c|c|}
\hline \multicolumn{3}{|l|}{ CPUE } & \multicolumn{2}{|c|}{$\begin{array}{l}\text { Estimated annual } \\
\text { catch }(\mathrm{t}),(\alpha=0.05)\end{array}$} \\
\hline Mean catch rate & Stake-net No. & Fishing days & lower & upper \\
\hline $24.32 \pm 20.66$ & $25-30$ & $260-300$ & 186.77 & 188.75 \\
\hline
\end{tabular}

\section{DISCUSSION}

In view of the standard length for fishing $\left(\mathrm{LM}_{50}\right)$ for main salable fishes in the Persian Gulf, the information in table 1 and figure 2 disclosed that considered stakenets, caught the young fishes mainly. Correspondingly caught fish whose length were over $\mathrm{LM}_{50}$ in practically all salable fish were equivalent to zero, denotation the utmost valued salable fish at capture were undersized their optimal size or below length at maturity. While stake-nets are classified into passive fishing gears, they would capture specimens devoid of effort. Hence, the mechanism of fishing by means of set-nets for instance stake-nets which are a type of passive fishing gears elucidate fishes might caught during their wandering. Moreover, fishes which are caught are in their early stage of life. This is on the subject of behavior of passive fishing gears; yet, this incidence is not with the intention of safeguard the ecosystem's biological reserves and ecological management purposes. On the other hand the size of the mesh opening in stake-nets pointed out that the mesh opening in the stake-nets constructed in the study area is actual tight which would result in entrance of a assortment of fishes and shrimps in any ages and stages of lifespan into the catch conformation.

Generally speaking, in this study the utmost relative abundance and weight based species were the Dussumieria acuta (10.05\%) and the Arius maculatus (5.9\%), respectively. The Clupeidae as well, with seven species remained as the richest family in the catch conformation. From the time when there is no data on fishing inside MPA, the results has been compared to the data outside it. Henceforth, results of the present study were to some degree comparable to other investigates in areas outside the range of mangrove woodlands ${ }^{23,24}$. Nevertheless the dissimilarities in the size or kind of fish could be seen, connotation some kinds of predator fish with the run-of-the-mill size in mangrove woodlands are seen that their company might possibly due to the nutritional purposes. The smaller size of the under study samples in comparison with similar reports as well, could be for the nature of the nursery ground of the mangrove woodlands, which is indeed the place to the juvenile and larval growth and expansion in marine environment. It is correspondingly remarkable that the overall number of caught species in this area (81 species) was more than that of the outside areas of the mangrove marine protected area ${ }^{24}$; for the reason that the mangrove forests are encompassed in tidal areas as well as are the biosphere reserves that possess high species diversity plus are rich in natural food besides ecological shelters ${ }^{25-27}$. Therefore, the higher quantity of the caught species could be due to the aforementioned notes. Pertaining to the catch conformation, it is determined that the stake-nets inside Qeshm marine protected area in general catch young fishes (Table 1). These results are in contract with reports from former researches ${ }^{23}$. Into the bargain considering the consequences, Monte Carlo simulation has been used to guesstimate the annual exclusive stake-net catch inside Qeshm Island MPA. The annual catch of stake-nets expected to be approximately 188 tons 
fishing inside MPA would harm it

(table 2). Although it is not an astonishing amount in the first look, yet bearing in mind catch conformation besides the size of fishes which caught, the significance of this educated guess would be specified. Likewise it is noteworthy that this guesstimate is lonely for stake-nets and the readers ought to think through that total annual catch for all kind of fishing gears inside MPA would be immeasurable enormous.

It is concluded that given that the study area has been incorporated in the Ramsar Wetlands International Convention ${ }^{22}$ and in terms of the protection at the level of national and international is of prime importance what's more, considering the data obtainable in this survey it can be concluded that this type of artisanal fishing gear, however did not catch a weighty volume of fishes in comparison with other fishing gears alike gill-nets, as a consequence of catching young fishes it might cause suffers Persian gulf marine reserves. As a result, it is recommended the decision maker agencies, trustees and residents of the Qeshm Islands' marine protected area contemplate a set of measures with the intention of preserve and reinforce God-given resources of the Persian Gulf and particularly mangrove woodlands' protected area as the biosphere reserve and nursery ground of the utmost salable fishes by means of co-management approach as well being steadfast undertaking it. Not counting the in effect concerns and attitudes of researchers in keeping with the terms and conditions governing the fisheries reserves and mangrove woodlands, discerning alternative livelihoods possibly will be inevitable in the adjacent yet to come.

\section{ACKNOWLEDGEMENTS}

We appreciate all the friends inside communities in the northern coastline of the Qeshm Island and Bandar Khamir for the unwavering backings and their warmth, plus all other friends who have lend a hand in the project.

\section{REFERENCES}

1- Valiela, I., J. L. Bowen and J. K. York (2001). "Mangrove Forests: One of the World's Threatened Major Tropical Environments." BioScience 51(10): 807-815.

2- Polidoro, B. a., K. E. Carpenter, F. Dahdouh-Guebas, J. C. Ellison, N. E. Koedam and J. W. Yong (2014). "Global patterns of mangrove extinction risk: implications for ecosystem services and biodiversity loss." Coastal Conservation 19: 15.

3- Maslo, B. and J. L. Lockwood (2014). Coastal conservation, Cambridge University Press.

4- Zahed, M. A., F. Rouhani, S. Mohajeri, F. Bateni and L. Mohajeri (2010). "An overview of Iranian mangrove ecosystems, northern part of the Persian Gulf and Oman Sea." Acta Ecologica Sinica 30(4): 240-244.

5- Kathiresan, K. and B. L. Bingham (2001). Biology of mangroves and mangrove ecosystems. Advances in marine biology 40: p. 81-251.

6- Hoegh-Guldberg, O. and J. F. Bruno (2010). The impact of climate change on the world's marine ecosystems. Science 328(5985): 1523-1528.

7- Miththapala, S., Mangroves. Coastal Ecosystems Series, ed. I. Ecosystems and Livelihoods Group Asia. 2008, Colombo.

8- FAO (2007). The world's Mangroves 1980-2005, FAO Rome, Italy.

9- Duke, N. C., J.-O. Meynecke, S. Dittmann, A. M. Ellison, K. Anger, U. Berger, S. Cannicci, K. Diele, K. C. Ewel and C. D. Field (2007). A world without mangroves? Science 317(5834): 41-42.

10-Cohen, J.E., et al., Estimates of coastal populations. Science, 1997. 278(5341): p. 12091213.

11-Ellison, A.M., Managing mangroves with benthic biodiversity in mind: moving beyond roving banditry. Journal of Sea Research, 2008. 59(1): p. 2-15. 
12-Alongi, D.M., Present state and future of the world's mangrove forests. Environmental conservation, 2002. 29(03): p. 331-349.

13-Hamilton, S. (2016). CGMFC-21, MFW, Global Mangrove Levels by Pixel ( 30m), 2000 - 2012, Harvard Dataverse.

14-Hamilton, S. E. and D. Casey (2016). "Creation of a high spatio-temporal resolution global database of continuous mangrove forest cover for the 21st century (CGMFC-21)." Global Ecology and Biogeography 25(6): 729-738.

15-Aburto-Oropeza, O., E. Ezcurra, G. Danemann, V. Valdez, J. Murray and E. Sala (2008). "Mangroves in the Gulf of California increase fishery yields." Proceedings of the National Academy of Sciences of the United States of America 105(30): 10456-10459.

16-Giri, C., E. Ochieng, L. L. Tieszen, Z. Zhu, A. Singh, T. Loveland, J. Masek and N. Duke (2011). "Status and distribution of mangrove forests of the world using earth observation satellite data." Global Ecology and Biogeography 20(1): 154-159.

17-Polidoro, B. A., K. E. Carpenter, L. Collins, N. C. Duke, A. M. Ellison, J. C. Ellison, E. J. Farnsworth, E. S. Fernando, K. Kathiresan, N. E. Koedam, S. R. Livingstone, T. Miyagi, G. E. Moore, V. Ngoc Nam, J. E. Ong, J. H. Primavera, S. G. Salmo, III, J. C. Sanciangco, S. Sukardjo, Y. Wang and J. W. H. Yong (2010). "The Loss of Species: Mangrove Extinction Risk and Geographic Areas of Global Concern." PLoS ONE 5(4): e10095.

18-Carpenter, K. E., F. Krupp, D. A. Jones and U. Zajonz (1997). Living marine resources of Kuwait, Eastern Saudi Arabia, Bahrain, Qatar and UAE. FAO Species Identification Field guide for Fishery Purposes .Rome, Italy: FAO Publication.

19-Wells, S., C. Ravilious and E. Corcoran (2006). In the front line: shoreline protection and other ecosystem services from mangroves and coral reefs, UNEP/Earthprint.

20-Reynolds, R. M. (1993). "Physical oceanography of the Gulf, Strait of Hormuz and the Gulf of Oman." Mitchell Expedition. Mar. Pollut. Bull. 27: 35-60.

21-Sheppard, C. R. C., A. R. G. Price and C. M. Roberts (1992). Marine ecology of the Arabian region. New York, Academic Press.

22-Ramsar Convention Secretariat (2013). The Ramsar Convention manual: a guide to the Convention on Wetlands (Ramsar, Iran, 1971). Ramsar Convention Secretariat, Gland, Switzerland.

23-Asadi, H. and H. Akbari (1999). Fishing by weires in Hormozgan province shoreline, Oman Fisheries Research Center: 1-26.

24-Mahin, M., A. Bagheri, A. Bahri and A. Salarpouri (2015). "Identification and catch composition of fish from set net (Moshta) fishery in Bandar Abbas, Persin Gulf." Journal of Aquatic Ecology 4(3): 90-97.

25-Feagin, R. A., N. Mukherjee, K. Shanker, A. H. Baird, J. Cinner, A. M. Kerr, N. Koedam, A. Sridhar, R. Arthur and L. P. Jayatissa (2010). "Shelter from the storm? Use and misuse of coastal vegetation bioshields for managing natural disasters." Conservation Letters 3(1): 111.

26-Ricklefs, R. E. and R. E. Latham (1993). "Global patterns of diversity in mangrove floras." Species diversity in ecological communities: historical and geographical perspectives. University of Chicago Press, Chicago: 215-229.

27-Yinxia, C. (1995). "Ecologycal Effects of the Mangrove on the Environment [J]." Marine Environmental Science 4. 